\title{
Using Social Learning Methodologies in Higher Education
}

\author{
http://dx.doi.org/10.3991/ijep.v5i2.4645 \\ M.E. Sousa-Vieira, J.C. López-Ardao, M. Fernández-Veiga, M. Rodríguez-Pérez and C. López-García \\ University of Vigo, Vigo, Spain
}

\begin{abstract}
It is a commonly accepted fact that contemporary cohorts of students witness and experience the benefits of information technologies in their learning processes. The socalled "digital natives" acquire, as a consequence of their early exposure to these technologies, different patterns of work, distinct attention conducts, new learning preferences and, generally, better skills for learning and working within rich online social contexts. So, it seems reasonable that the traditional education systems evolve and shape their practice to appropriately support those new patterns. Despite the fact that online social networks (OSNs) are widely recognized as powerful tools for adding a new social dimension to learning management systems (LMSs), OSNs do not fully integrate the specific features of the learning process yet and LMSs do not exploit the advantages of an active social environment for reinforcing the learning experience. In this paper, we therefore deal with the design, development and use of a software platform which enlarges and adapts the basic features of an OSN in order to be useful for very general learning environments. The software allows the creation, assessment and reporting of a range of collaborative activities based on social interactions among the students and offers a reward mechanism by means of a ranking and awarding system. We argue that this approach is helpful in increasing the students' motivation, besides improving their learning experience and performance. The software has been tested in an undergraduate course on computer networks. Different tests confirm that the impact on learning success is statistically significant and positive.
\end{abstract}

Index Terms-Gamification, informal learning, online social networks.

\section{INTRODUCTION}

Several pedagogic approaches have been arising during the recent years to explain how to introduce efficiently and seamlessly web 2.0 technologies and online social networks (OSNs) into the learning process, at all stages. Despite their particular differences, a common tenet of these views is their advocacy of a novel term which are "informal", or "invisible" or "natural" learning. These are, in essence, equivalent terms which underline the promising advantages of networked learning, in other words, of learning from the spontaneous relationships woven either with peers or experts in a given domain of knowledge. As a matter of fact, most of these views argue for a personalized education, more focused on the student, but also connected to other co-created and collaborative areas. In summary, the social aspects of learning are put at the forefront.

Usually, learning has been an activity mostly focused on the process of acquiring new, objective knowledge in a subject. Such knowledge had to be built by memorizing facts, repeating tasks and studying with an individual effort. Interpersonal, authoritative communications about the subject of study happen only between the teacher and the student, emanating from the former. So, the relationship tends to be formal, rigidly structured, pre-determined and confined to the classroom. In contrast, when one considers networked learning, the different motivational theories mentioned above emphasize the role of knowledge gained through social relationships (real or virtual), that is, private conversations, public debates, speculative exchange of ideas, sharing knowledge, collaboration, cooperation, etc., irrespective of whether these take place between peers or with experts. Not only is informal learning useful to apprehend tacit, implicit or unspoken knowledge, but also to improve objective, explicit learning, because in increasingly many disciplines the know-how and the know-who [1] are as important as its scientific or cultural foundations. In informal learning, the building of skills draws more strongly on collective work and information exchange. Relationships among the learners may be informal, spontaneous, unexpected, decentralized, non-hierarchical, detached from a teacher. The student is the leading actor, and their personal learning network (PLN), their mesh of contacts to discuss some subjects, plays a fundamental role. This PLN helps us in classifying the information flows that reach us, so as to identify the most useful sources, recognize new learning resources, or get rid of doubts. Our PLN shares with us knowledge and experience, evolved through continuous conversation, discussion and opinion. All this is spurred by the fact that OSNs are changing our communication habits, particularly among the youngsters who are almost permanently engaged with their online social partners. Because the learning process is basically a human communication process, our PLN can become a powerful tool for enhancing every aspect of it.

Informal learning is not a radical re-thinking of how we learn and teach: it has always been present with us, at workplaces with colleagues, at schools and colleges with our fellows, in everyday life with friends and relatives. What OSNs and web 2.0 technology allow us is to go further, beyond a PLN determined by personal relationships toward a PLN which merges the personal and virtual relationships. Without OSNs, it was difficult to bring society's complexity into the classroom, thus hampering any kind of informal learning; with OSNs, a rich PLN can be established easily. More importantly, OSNs entail unspecific skills such as search, store, debate, collaborate, share or publish - which are all part of our work methodology.

An essential feature of the digital natives $[2,3]$ is their learning from surrounding contexts, as a response to a 
PAPER

request for solving a specific problem (this explains in part why a substantial research effort was devoted to the area of problem-based learning in the last few years). But, the best way of tackling those problems is on-demand, browsing the Internet to find documents, videos, games or whatever other stuff related to the task. Alternatively, the students may explore an OSN looking for some people willing to help. Therefore, several learning experiences are conducted in parallel, without a particular order, and always within the frame of a specific problem. These learning experiences are relatively short, and there is no awareness of the need of retain and memorize something for later use, since the same search may be repeated as often as necessary. So, while this new way of learning might be considered to be a symptom of superficial behavior, some scholars $[4,5,6,7]$ regard it as a logical evolution in the growth of our collective intelligence, and address this kind of learning not as a hindrance, but as a trend that one should accept and adapt to. It is also important to realize that these students combine their online tools with other academic ways of learning in a natural way.

The desire of quick satisfaction is a typical feature of digital natives and has serious consequences on education, since it works against those subjects which involve complex or highly abstract knowledge structures, or those requiring extensive practice before achieving command. To solve this issue, new learning environments that make the acquisition of these skills more appealing are needed. In this framework, a gamification strategy $[8,9,10,11]$, i.e., the use of games or game elements to facilitate learning, is usually a way to success. The most recent Horizon Reports $[12,13]$ highlight social gaming as one of the future trends in education, emphasizing the students' active participation as a key point. Though one of the motivating factors for learning is to reach a short-term goal, many times the motivation is also to obtain social recognition for having solved a problem, alone or in a team. Thus, a high social ranking [14] is a strong pulling force that fosters fast and effective learning. There is indeed an important link between informal learning processes, personal motivation and social ranking. At least, the informal learning approach turns out to be an enabling tool to promote emulation among the students, hence moving the student into acceptance by the group and encouraging them to adopt the work habits in use within the community. Furthermore, an informal learning environment promptly rewards its members' progress in knowledge by endowing them with trust and self-confidence.

In brief, we believe that the development of informal learning activities and social games, if designed to favor collaborative exchange and the creation of knowledge contents among a group of students, can be highly positive. These activities have to be directed towards the learning of experimental procedures, a hands-on experience with real devices or equipment and the completion of projects. Instead, the use of social games as learning tool is more intended to engage the students into the platform so that their participation increases and the development of unspecific features such as leadership, critical thinking, and ability to work in teams gets reinforced. Note that a game can be simply conceived as a means to distribute a pool of marks among the best performers in a proposed activity in order to finally come up with a ranking among the group members. To compare one's performance with that of other colleagues is often the best way to stir con- tention using the sheer desire to out-perform another person (or, at least, to emulate their results). Likewise, a comparison with other students that show a slightly worse performance reassures self-confidence. In any case, the students feel compelled to follow the average pace of the group, which is positive in itself.

Unlike traditional approaches to learning, any methodology of networked learning must necessarily be supported by a software platform. Here, the main drawback comes from the inadequacy of most commercial and free software packages (e.g., LMSs such as Moodle or Blackboard) which cannot offer functionality to embed OSN features. With them, the user has no possibility to interact with other students and weave personal bonds to learn from them, or to set activities that possess informal patterns. In addition, those software platforms seldom offer virtual spaces for undertaking work in teams. To these shortcomings, one could also add that both students and professors acquainted with information and communication technology find themselves trapped using 1.0 tools, whereas newer, richer 2.0 technology must be used. So, given the lack of learning management systems especially devised and adapted to the informal learning paradigm, some pioneering teachers have decided to take to their classrooms their own innovative custom-made solutions. Only recently genuine social learning environments (SLEs) have become available to the education community $[15,16,17]$, i.e. software-based integrated tools for sharing and creating both contents and educational experiences in a truly collaborative fashion. Some evidence that SLEs are gaining more acceptance and appeal is given by the offering of typical OSN capabilities in many wellknown LMSs. However, as will be discussed below, none of these platforms is well suited to our aims, and that is the reason why we developed our own SLE SocialWire, a social learning system based on the free software Elgg [18], a popular engine for the creation of OSNs. SocialWire [19] was purposely designed to include the networked learning paradigm as a complement to conventional, more formal learning activities and forms to display content, but taking games and social meritocracy as conducting threads. To that end, the new software allows the creation, assessment and reporting of a range of collaborative activities based on social interactions among the students, and offers a reward mechanism by means of ranking and creating a reputation. We argue that this approach is helpful in increasing the students' motivation, besides improving the learning experience and performance.

We have been running the platform since 2012 as a companion tool in several undergraduate and master courses on Computer Networking, with great acceptance from the students and good results overall. Nonetheless, aside from our personal focus on engineering education, the design of the tool is neutral and generic and it might be useful in other fields. In fact, it has been used in different subject areas in our university during this period. The feedback obtained has encouraged us to enhance the initial functionality [20] and to develop new modules.

The paper is organized as follows. Section II gives a high-level description of the software platform that we have developed to put the social learning experience into practice. Section III reports and discuss the results of applying this methodology in a college course, in terms of 
satisfaction and success of the students. Finally, some concluding remarks are presented in Section IV.

\section{SOCIALWIRE}

\section{A. The Learning Platform}

Basically, SocialWire was developed in four blocks:

The online social network. SocialWire supports the core of Elgg for reusing the fundamental elements of a generic OSN. Every group (classroom group) defined in the system has its own wall to maintain open communication among all its members. The group can also use common tools in the social web for its virtual classroom activities: classroom blog, collaborative publishing and document editing, creation of web pages, social tagging, file repositories with a hierarchical structure (including a viewer for images, audio, video and the usual document formats), event calendar. All the activities unfolded in the classroom eventually get reflected on the public wall, so they can be commented, highlighted or voted. Sharing videos, uploading a file, saving and sending a link are extremely simple actions which the user can invoke thorough an user interface deliberately similar to an OSN user interface, in accordance to recent studies reporting that students and teachers prefer learning platforms with a close resemblance to their favorite OSN. The user-friendliness is higher, as a bonus, and the learning curve of the platform itself is greatly softened.

The formal learning processes. To furnish SocialWire with the usual features of an LMS, we have developed custom software modules that extend the bare OSN based on Elgg. Specifically, there exist modules submitting tasks (either online or offline) for the creation and assessment of tests, for the creation and processing of forms or polls, for building an e-portfolio, for designing rubrics for evaluation, and more. Another software module gives the teachers the possibility of structuring the learning units in their courses, for instance weekly, monthly, by topic etc., and to add to each unit as many information resources as they like. The units can be hidden and made visible only at the point when they become relevant.

The informal learning processes, which receive the utmost importance. SocialWire opens the possibility of carrying out other sorts of activities requiring a higher part of social interaction. This is done by means of two modules, the questions and contests modules. Besides the usual grading procedure used in formal courses (on a numeric scale or by discrete levels) the students can receive "points" for their work in SocialWire. The points accumulated along the course determine their position in the students' ranking. This ranking serves primarily to send signals to the students about their relative performance, in a way that directly stimulates comparisons and that automatically conveys the meaning of their social reputation. Recently, a badge module that implements mechanisms to define a policy for assigning mentions of distinction has been included.

The collaborative work processes. Most of the popular software platforms for collaborative work fail to give real, effective support for working collaboratively. First, the users are not given a virtual workspace where direct communication and sharing between colleagues can happen, so they must resort to external programs to solve this (or in extreme cases, physical meetings). Secondly, teach- ers are not provided with the opportunity to manage, coordinate, assess, evaluate, share or communicate with the work groups. SocialWire does permit subgroups, i.e., smaller groups within an existing group. The instructors are in charge of deciding how many groups will be created, their sizes and their membership policies, if any is due. Every activity supported by SocialWire can be assigned to a group or to an individual, and in the former case any group member is entitled to participate in the role of group's representative. Additionally, every subgroup is internally a group and has a private space so that their members and the instructors can communicate.

Next, we describe in detail the software modules developed to introduce informal learning activities and in our courses.

\section{B. Informal Learning Modules}

Questions module. The functionality of this module is straightforward. With it, any group member (instructor or student) can make a public question on any subject. If the author is a student, the question must first be approved by an instructor before a time period for gathering answers begins. This time period is configurable, and while it lasts any member in the group can contribute their answers (or their comments to previous answers) in a public or private way. Meanwhile, the teacher can change the visibility of some answers, thus filtering out how much information is revealed to the rest of the group or using a simple mechanism to stir controversy or to finish digressions. The answers can be individual or collective and the finest one may be highlighted by the instructors. The questions end when the instructors have decided so, for instance, competition can be stimulated by closing a question once the first correct answer is made.

There is generally too much flexibility about how to grade (with points) a question and its answers. Though usually the grading is postponed to a due date, when the answering time has ended, in SocialWire the answers may receive points even during the active period of a question. This is convenient in order to start up the game dynamics among the participants. Obviously, when a question is closed, no more answers are accepted, but comments to known answers are allowed. The points granted to an answer have two purposes in this scheme. For one thing, it is a means for classifying the relevance, importance or correctness of the answer. The points are thus a numerical index for sorting the answers in accordance to these criteria. At the same time, this module works jointly with the ranking module, in such a way that the points given to a student form their position in the ranking.

Contest module. In SocialWire, a contest can be seen as a strategic game that seeks to collect clues, ideas, complete solutions or suggestions regarding a complex problem or a problem with a non-unique solution. Although these games may be run in a cooperative fashion, the goal of the game would be to "conquest" collaboratively a common solution to the problem at hand; or, in a competitive fashion, there are incentives for confusing, misguide or taking profit from other participants - we always assume that contests are of the first kind. The answers sent to a contest may again be individual or collective. At any time, the instructors can control their visibility, thus filtering how much information is revealed to the rest of the group. 
For granting points, there are several options. One is that the instructor distributes a fixed amount of points for the answers, depending on their quality, relevance or completeness. Alternatively, the answers (possibly corrected, amended or filtered by the teachers) can enter a voting phase, where all the group members may give out their votes according to private preferences. In such a case, the voter's identity could be concealed in order to avoid conflicts. The context, goals and topic of the contest indicates the best procedure so as to determine the rewarding policy. This contest module is also related to the ranking module. Hence, when the voting phase finishes the ranking module awards points proportional to the votes received by each answer.

Ranking module. One of our major motivations for developing SocialWire was the belief that online social interactions among the students foster the effectiveness of any learning system. In an online system, the opportunity to contrast one's advances to that of others is essential to motivate the students. One of the simplest devices, and most productive too, for stimulating the group dynamics is to use a ranking of its members. The ranking exhibits many information dimensions simultaneously. First, the ranking exposes the achievements of any user, in that their position in the ranking is an indirect but good signal about their performance across the tasks proposed so far compared to that by their classmates. For the student, this position is useful to measure their own expectations in the course. Immediate feedback is possible about the learning pace of the whole group. Secondly, the ranking establishes a hierarchy in the group. Once known, the ranking unconsciously influences the entire group: the answers, tasks or contributions coming from members highly positioned in the rank will likely be taken more trustworthy by the other group members. In the reverse direction, low-positioned members are implicitly forced to improve their work if they aim to keep the group's esteem.

The ranking module that we developed gathers all the points granted to the students in any other module, sorts the results and displays the lists properly, in aggregated or in detailed forms. Ranking points may be transformed into final course grades at any moment by the course instructors.

Badges module. The badges plug-in implements mechanisms to define the policy for assigning mentions of distinction to specific users, as a prize for their overall activity or performance within a group. The operations are quite simple, in fact: badges may be manual or automatic. In the former case, the group administrators give out the credentials at their discretion. In the later case, specific rules have been predefined that grant the badge to each user that fulfills the requirements. For example, typical requirements would be to achieve a given number of points. Other example policies could be devised to specifically value related tasks, such as granting the badge once a student has completed a given set of proposed tasks. Badges may be recursive: new badges could be the result of having gained other badges previously.

Visibility is a key feature of using badges as a stimulus within the platform, and to this end the plug-in incorporates a classification function so that a list of users with their associated merits can easily displayed and consulted.

\section{APPLICATION}

During the academic year 2012/13 we tested the methodology in an undergraduate course on Computer Networks.

The course has a weekly schedule and lasts 14 weeks.

Lectures are given as follows:

- A two-hour in-class lecture. The lecture explains the basic concepts of a specific topic, gives relevant examples and discusses alternative approaches.

- A two-hour laboratory session, in small study groups (20 students). This is a complementary session where the students solve written exercises, work with real networking equipment and make a small programming assignment.

SocialWire is used as the software platform along the course. The students (and teachers) belong to a single group wherein general communication about the topics covered takes place. To encourage networked learning activities and collaborative work, we planned different social activities in SocialWire whereby the students may gain their "points". The resulting ranking of points is made public to the group. Activities are of two types:

- Collaborative answering of questions. This activity consists of posing and solving any question, doubt or problem about the subject. The students send their questions, and so do the instructors occasionally. From the questions posed by the students, each question aligned to the course objectives receives one point; and each apt answer to it (not absolutely correct, since the effort to participate and try to answer is also valuable) gets one or two points, depending on its quality and completeness. Instead, the answers to questions posed by the instructor receive 5 or 10 points, depending in this case on the difficulty. The instructor can reward the timeliness in answering a question, too. Correct answers are clearly marked, so that there is no misunderstanding. The partial ranking is public.

- Gathering of information resources by theme. To complete this activity, every student has to enroll in some subgroup organized by topics (taken from the material covered in the course). Along two months, the students must collect and share with all the class information resources about the topic of their choice. It could be, for example, newspaper articles, tutorials, Internet videos, solved exercises/problems, presentations, slides, or any other content. With the information resource, a brief description is mandatory for summarizing its interest. Finally, all the subgroup members have to synthesize this diverse information and write a blog entry about their topic. The variety, quality and popularity of the resources are rewarded with a maximum of 20 points, which are assigned equally to all the members of the sub-group, except clear imbalances are observed in the work realized by each one.

Though this subject may be passed with a single final examination covering all the materials, students are encouraged to follow the continuous assessment path. In the current academic year, the weight of the continuous assessment was $40 \%$, the remaining $60 \%$ being awarded as the result of a final exam held at two different dates (May and July, non-exclusive). From the $40 \%$ in the continuous assessment, $10 \%$ of the final grade results from the game points gathered by engaging in the social activities commented in the previous sections. The rest is split into a 
$20 \%$ from a midterm exam and a $10 \%$ from a programming assignment.

Therefore, the ranking points have to be converted into a numerical grade within the range $[0,1]$. In the past academic year, when this methodology was also tested, the conversion was directly proportional to the number of points accumulated, i.e., the top student in the ranking received a score of 1 , and the rest a score which is the ratio between their points and the highest mark in points. This rule is very sensitive to high outliers, and so many students got a tiny pay off for their work. Indeed, with a weight of only $10 \%$, the score was only a minor contribution toward the final grade, a clear disincentive to participate again. While it is true that one point in the final grade might seem too scarce a pay off for the best student, we believe it is important that the full score is easily achievable by a significant fraction of the class.

Thus, in the present academic year, in order to convert the point marks into a grade, if Pav is the average number of ranking points per student and Pmax is the maximum, we compute $\mathrm{M}=\min \{\mathrm{Pav}, \mathrm{Pmax} / 2\}$. In the conversion scale, $M$ represents 0.5 points, and every student having at least $2 \mathrm{M}$ game points gets the full 1 grade possible with this part. In doing so, we expect to preserve the incentivedriven effect whereby the average-performing student is still engaged and the best students attain due pay offs.

\section{A. Participation in the Social Activities}

The participation of students in the designed collaborative activities was as follows:

- Collaborative answering of questions. As Fig. 1 shows, along the course the students submitted 48 questions and 110 answers, and the instructors 4 questions. The quality of the answers was remarkable, with more than $50 \%$ of answers worthy of game points. The slowdown of activity during late March coincides with the midterm exam date and Easter holidays. As we can see, the instructors were especially involved in returning feedback responses in a timely manner, which was particularly appreciated by the students.

In Fig. 2 (activity before the midterm) and Fig. 3 (activity after the midterm) every node is a student identified by their final rank (in game points). The light green points correspond to students that accomplished the subject in May, the dark green is for students who passed in July, and the white points are for students who dropped out of the course or failed the subject in the end. The color in the questions (circles) and the answers (edges) serves to classify them on the basis of the points received.

The first picture clearly shows many students who could not get their accomplishment certificates in the course, who abandoned the activity in the second half of the term or who, as a matter of fact, are low-ranked (in game points). Most of those students finally opted for the single examination as form of assessment, and that is why they refused the other activities offered in the continuous assessment option. In addition, the first picture does not show all the students who did engage in the game and ended up passing the course, because nearly all the students entering the social game in the second half of the term were able to pass in May or July. Actually, some of the top-ranked students had received poor grades at midterm and struggled to improve their continuous assessment grade by contributing actively to the questions-andanswers game, which they definitely did. This group would pass the subject with high grades in the final exam. It is also remarkable that the students shown in the second picture (except two of them, who only contributed questions to the game) passed the course in May or July.. In both pictures, the students with high ranks achieved also high grades in the other activities proposed for continuous assessment, as well as in the final exam.

Figs. 4-6 show the number of questions, answers and received answers per student. Related to the number of questions, the undesirable behavior of only contributing with many questions to the game is observed in just one student, who dropped off the course at the beginning of the term.

We have also measured the number of answers between the same students, resulting in: $1 \rightarrow 63$ pairs, $2 \rightarrow 10$ pairs, $3 \rightarrow 5$ pairs and $6 \rightarrow 2$ pairs. Two of the three students who constitute the two last pairs occupy the first two positions in the ranking, and the other contributed to the game with many other answers. Therefore, we can also reject the other undesirable behavior of cooperating to post and answer questions.

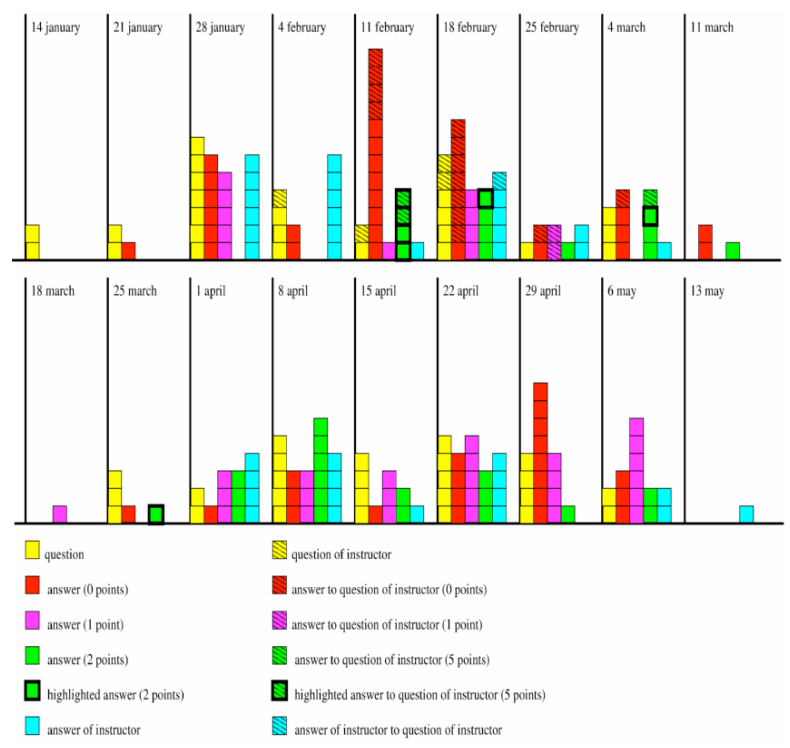

Figure 1. Collaborative answering of questions activity

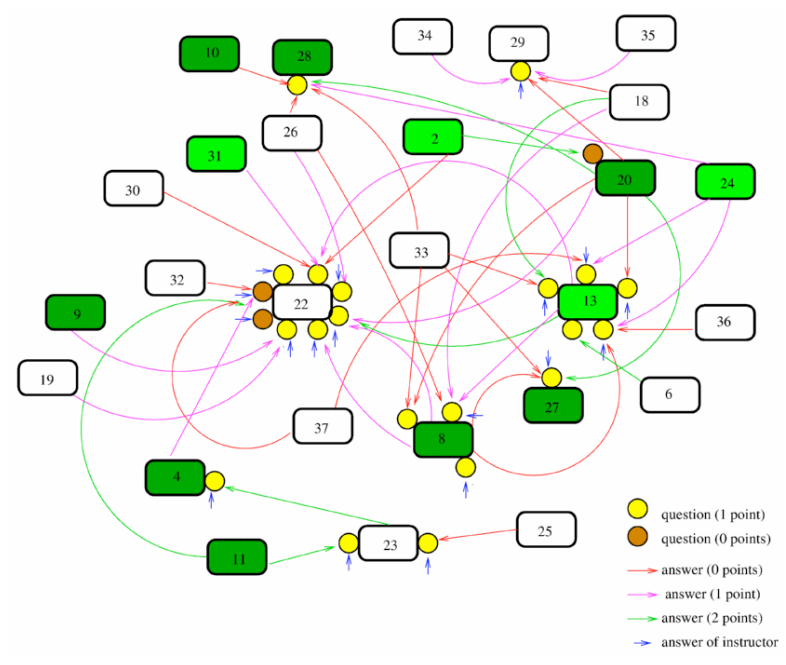

Figure 2. Activity before midterm 


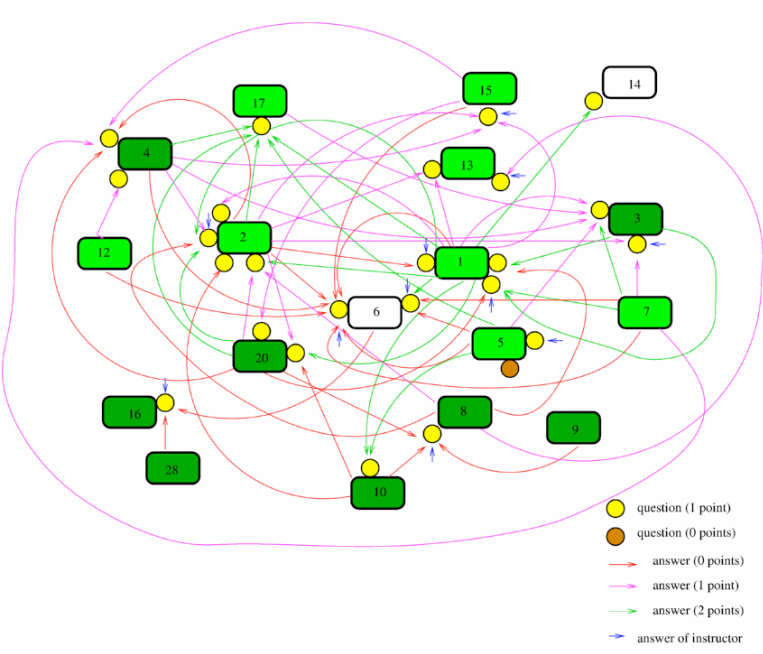

Figure 3. Activity after midterm

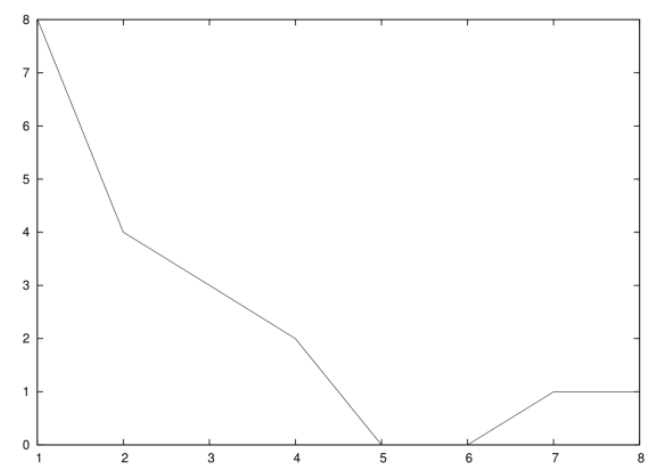

Figure 4. Number of answers per student

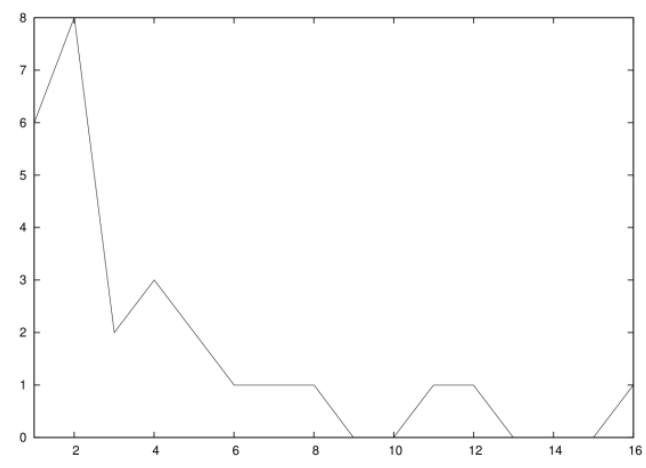

Figure 5. Number of answers per student

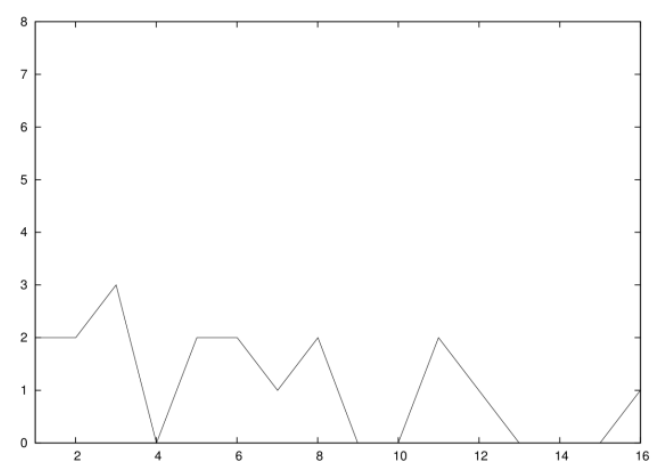

Figure 6. Number of received answers per student
Finally, to measure the degree of correlation between the number of questions and answers per student we have used the test of correlation and the Kendall's test. In both cases we have selected a cut for the level of significance of $5 \%$. The correlation test quantifies the coefficient of correlation, $\rho$, between two standardized variables. Under the null hypothesis (the variables are uncorrelated) the test statistic $t$ follows a t-Student distribution. The Kendall's test quantifies the statistical significance of the correlation between two variables. Under the null hypothesis (independence) the test statistic $z$ is Gaussian, and similar remarks apply.

- Correlation between the number of questions and the number of answer of the students who contributed to the game:

- Correlation test: null correlation can not be rejected $(\rho=0.33, t=2.02, \operatorname{Pr}[|t|>2.04]=0.05)$.

- Kendall's correlation test by ranges: independence can not be rejected $(z=0.63, \operatorname{Pr}[|z|>1.95]=0.05)$.

- Correlation between the number of answers and the number of received answer of the students who contributed to the game:

- Correlation test: null correlation can not be rejected $(\rho=0.29, \mathrm{t}=1.73, \operatorname{Pr}[|\mathrm{t}|>2.04]=0.05)$.

- Kendall's correlation test by ranges: independence can not be rejected $(z=0.49, \operatorname{Pr}[|z|>1.95]=0.05)$.

- Collaborative gathering of thematic information resources. Despite the level of participation in this activity (20 students, out of whom 16 finally passed the course), was far lower than in the former, the overall quality of the selected information resources had a high value. Thus, the collection formed a valuable repository for comprehending and studying the subject. Part of the reason for low participation was that the activity was done in the last month of the term, when students are often too busy. In that respect, we expect more participation if the activity is planned right from the start of the term, as we intend to do in next offerings. We will also be more careful in ensuring the group's composition (what students collaborate about a topic) is more complementary both in their interests and their abilities.

\section{B. Impact on Learning Results}

Checking the final list of grades in the disparate activities proposed along the course, we noticed that all the students who passed in the first call (May) followed the continuous assessment path and were actively engaged in the games. Most of the remaining students of this sort passed in the second call (July). However, in contrast to the results in May, in the July call several students who opted for the single examination were also successful.

This may be seen as a hint that continuous assessment forces the students to keep the pace in the course, and facilitates their final accomplishment when they are faced with short time to prepare themselves for the final exam, since they have less knowledge to command. The July call gives the students additional time to study and the chance to focus on a few subjects only.

We now show the results of different proofs to measure the influence of the participation in the continuous assessment activities and games in the learning results. The size of the population is 86 students. 
1) Correlations among the grades in each part.

To measure the degree of correlation between the grades of each part we have used the test of linear regression and the Kendall's test. In both cases we have selected a cut for the level of significance of 5\%. The test of linear regression quantifies the statistical significance of a linear fit of a response variable on one factor variable. $\beta$ is the linear coefficient and $\mathrm{R}^{2}$ is a measure of the variability of the response variable that can be explained with the factor variables. Under the null hypothesis (meaning that there is not such linear dependence) the test statistic t follows a tStudent distribution.

All proofs confirm that there is a significant positive dependence between the grades of the continuous assessment activities (midterm exam and programming assignment), the game points in the social activities and the final grade in the course.

- Correlation between the average grade in the other continuous assessment activities (midterm exam and programming assignment) and the game points in the social activities.

- Linear regression test: linear regression can not be rejected $\left(\beta=2.52, t=4.81, \operatorname{Pr}[|t|>2.04]=0.05, R^{2}=\right.$ $0.38)$.

- Kendall's correlation test by ranges: independence is rejected $(z=2.01, \operatorname{Pr}[|z|>1.95]=0.05)$

- Correlation between the average grade in the other continuous assessment activities (midterm exam and programming assignment) and the final grade in the course.

- Linear regression test: linear regression can not be rejected $\left(\beta=0.69, \mathrm{t}=8.22, \operatorname{Pr}[|\mathrm{t}|>2.04]=0.05, \mathrm{R}^{2}=\right.$ $0.66)$.

- Kendall's correlation test by ranges: independence is rejected $(z=4.78, \operatorname{Pr}[|z|>1.95]=0.05)$.

- Correlation between the game points in the social activities and the final grade in the course.

- Linear regression test: linear regression can not be rejected $\left(\beta=0.14, t=6.86, \operatorname{Pr}[|t|>2.04]=0.05, R^{2}=\right.$ $0.36)$.

- Kendall's correlation test by ranges: independence is rejected $(z=3.92, \operatorname{Pr}[|z|>1.95]=0.05)$.

2) Difference in the final grade according to continuous assessment and games/single examination

For this proof we have used the t-test and the Smirnov's test and again in both cases we have selected a cut for the level of significance of $5 \%$. The t-test quantifies the statistical significance of the equality of the mean values of two variables. Under the null hypothesis (equal mean values) the test statistic t follows a t-Student distribution. The Smirnov's test quantifies the statistical significance of the equality of the distributions of two variables. Under the null hypothesis (equal distributions) values of the test statistic $s$ higher than the tabulated value $\lambda_{\text {a }}$ are very unlikely.

All proofs confirm that there are significant differences between the final grade of the students who followed the continuous assessment (and the level of significance increases with the degree of participation) and the final grade of the students who chose the single examination alternative.
- t-test for comparing the final average grades, considering

- Participation/absent in the activities scheduled for continuous assessment (midterm exam and programming assignment): the difference is statistically significant $(\mathrm{t}=2.14, \operatorname{Pr}[|\mathrm{t}|>2]<0.05)$.

- Participation/absent in the social activities: the difference is statistically significant $\quad(t=$ 6.54, $\operatorname{Pr}[|t|>2]<0.05)$.

- Participation/absent in some of the activities scheduled for continuous assessment and/or in some of the social activities: the difference is statistically significant $(\mathrm{t}$ $=2.42, \operatorname{Pr}[|t|>2]<0.05$ ).

- Participation/absent in all the activities scheduled for continuous assessment and in all the social activities: the difference is statistically significant $\quad(\mathrm{t}=$ 13.96, $\operatorname{Pr}[|t|>2]<0.05)$.

- Smirnov's test on the distribution of final grades considering

- Participation/absent in the activities scheduled for continuous assessment (midterm exam and programming assignment): equality is rejected $\quad(\mathrm{s}=1.61>\lambda$. $=1.36)$.

- Participation/absent in the social activities: equality is rejected $\left(\mathrm{s}=2.56>\lambda_{\mathrm{s}}=1.36\right)$.

- Participation/absent in some of the activities scheduled for continuous assessment and/or in some of the social activities: equality is rejected $\quad(\mathrm{s}=1.87>$ $\left.\lambda_{\varepsilon}=1.36\right)$.

- Participation/absent in all the activities scheduled for continuous assessment and in all the social activities: equality is rejected $\left(\mathrm{s}=2.17>\lambda_{\mathrm{e}}=1.36\right)$.

3) Dependence between continuous assessment and games and pass/fail the subject

For this proof we have used a test of dependence in contingence tables. Under the null hypothesis (independence) the test statistic $\chi^{2}$ follows a $\chi^{2}$-distribution. The test confirms the dependence between the participation in the continuous assessment and social activities and overcome successfully the subject. Again, we can observe that the level of significance increases with the degree of engagement in all the activities proposed during the whole term.

- Test of dependence in contingency tables between passing the subject and

- Participation/absent in the activities scheduled for continuous assessment (midterm exam and programming assignment): independence is rejected $\left(\chi^{2}=8.16\right.$, $\left.\operatorname{Pr}\left[\chi^{2}>3.84\right]=0.05\right)$.

- Participation/absent in the social activities: independence is rejected

$\left(\chi^{2}=\right.$ 15.56, $\left.\operatorname{Pr}\left[\chi^{2}>3.84\right]=0.05\right)$.

- Participation/absent in some of the activities scheduled for continuous assessment and/or in some of the social activities: independence is rejected $\left(\chi^{2}=\right.$ 11.82, $\left.\operatorname{Pr}\left[\chi^{2}>3.84\right]=0.05\right)$.

- Participation/absent in all the activities scheduled for continuous assessment and in all the social activities: independence is rejected $\left(\chi^{2}=\right.$ 18.44, $\left.\operatorname{Pr}\left[\chi^{2}>3.84\right]=0.05\right)$. 
Thus, we can claim that the participation on the collaborative activities developed within the software platform is highly correlated with the probability of passing the subject. Similarly, the option of continuous assessment seems to show more effectiveness in acquiring the learning objectives, in that most of the students that finally pass the subject opt for following this mode of assessment.

\section{4) Repeaters' behavior}

To assess the impact of being a repeater or not in the final averages, we have used the t-test and the Smirnov's test, obtaining the following results:

- $\quad t$-test: the difference is not statistically significant $(\mathrm{t}=0.26, \operatorname{Pr}[|\mathrm{t}|>2]<0.05)$.

- Smirnov's test: equality can not be rejected ( $\mathrm{s}=$ $\left.0.34<\lambda_{t}=1.36\right)$.

Moreover, for measuring the (lack of) dependence between being a repeating student and passing/failing the subject we have used a test of dependence in contingence tables, resulting:

- Independence can not be rejected $\left(\chi^{2}=0.16, \operatorname{Pr}[\right.$ $\left.\left.\chi^{2}>3.84\right]=0.05\right)$.

These results are accordant with the instructor's perception that the repeating students merge into the dynamics of the new course exactly as any newcomer student, since typically they had chosen the single assessment option in their previous exposure, so the social activities are entirely new for them.

\section{5) Other advantages of the methodology}

Besides the advantages exposed previously, some other qualitative benefits of the social activities developed can be remarked:

- Collaborative learning: in the first activity, answering questions and common doubts helps in shaping an overall comprehension of the subject. In the second activity, the students are learning either in the searching process or in reading their classmates' contributions.

- Critical thinking: in the first activity, critical thinking is improved when the answers submitted by other students receive comment or criticism. The second activity promotes critical thinking in that it involves judgement about the quality of the selected resources.

- Self-expression: the urge to express originality or even identity within the group is fulfilled by the two activities.

- Softening the consequences of mistakes: no penalty is incurred if an answer is incorrect, mistakes are as necessary to learn as right answers are.

\section{SATISFACTION POLL}

It is important to poll the students about their satisfaction with the platform and the learning methodology. With that aim, we used an optional poll to be answered anonymously and directly accessible on the platform along the last months of the term (from early May to the end of July). The questions were the following:

1) The SocialWire platform is easy to use $(1-5)(\mu=2.87$, $\sigma=0.81)$

2) My participation in the social activities conducted on SocialWire was $(1-3)(\mu=1.56, \sigma=0.82)$
3) The activities proposed on SocialWire are helpful to study the material $(1-5)(\mu=2.75, \sigma=1.34)$

4) The methodology of continuous assessment helps to keep the pace of the subject $(1-5)(\mu=2.37, \sigma=1.31)$

5) I would like more activities in SocialWire (1-5) $(\mu=2.06, \sigma=1.24)$

6) The programming assignment was interesting (1.5) $(\mu=2.94, \sigma=1.53)$

7) The contents of this subject are clearly explained (1-5) $(\mu=3.31, \sigma=0.79)$

$8)$ The problems and exercises in classroom are useful and complete $(1-5)(\mu=2.81, \sigma=1.11)$

9) I believe that I have learnt in this subject $(1-3)(\mu=2.12$, $\sigma=0.51)$

10) I would like to learn further about the subject in other courses $(1-2)(\mu=1.75, \sigma=0.45)$

11) I chose the continuous assessment (1-2) $(\mu=1.52$, $\sigma=0.52$ )

Most of the questions are in a five-points scale (from absolutely disagree to absolutely agree), two are in a three-points scale (low, medium and high) and the last two are questions of not/yes answer. The histogram of the answers is show in Fig. 7.

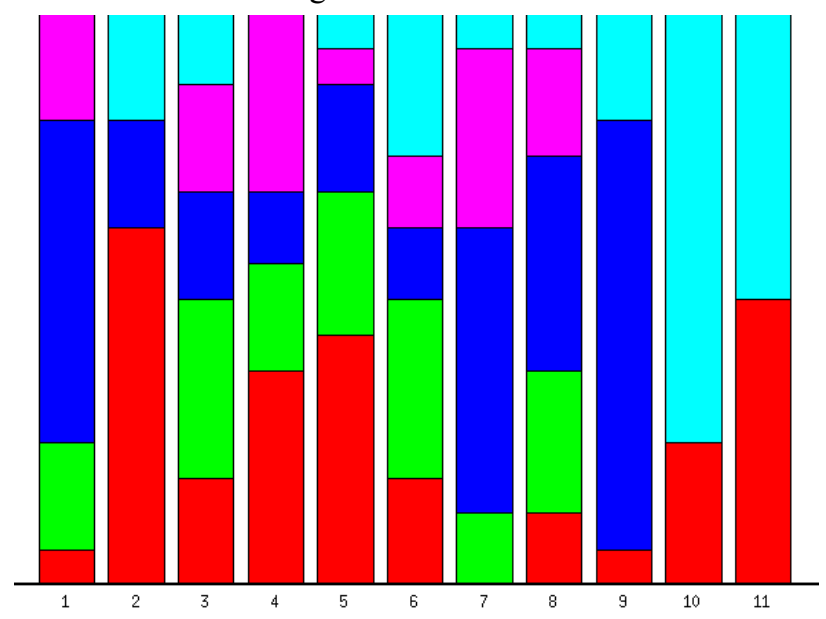

Figure 7. Histogram of the poll answers

The mean value $(\mu)$ is almost always over the half of the range, indicating that the students' perception about the social experience and the subject learning methodology in general was positive. Moreover, we can conclude that the students consider that the activities proposed in SocialWire are adequate and sufficient. And finally, the last questions show that most of the students that complete the poll have the impression that have learnt enough, but would like to learnt further about the subject in successive courses.

It is important to highlight that a half of the answers are from students that did not follow the continuous assessment alternative.

\section{Conclusions}

In this paper, we have argued that, despite the vagueness of the concept and the controversy, informal learning and gamification can be an effective strategy to complement traditional, formal education. When the collaborative activities are smart, students get easily involved and be- 
come very active participants in them, the fact that they are playing in a game being nearly oblivious.

We have described the architecture of SocialWire, a software system especially built to articulate the creation and the workflow of social/gaming learning activities that we have been running since 2012 as a companion tool in several undergraduate and master courses.

Moreover, we have reported our satisfactory experiences and results after using the platform in teaching a course about Computer Networks. Different tests confirm that the impact on the learning success is statistically significant and positive. In our view, this gives some experimental support to the benefits enclosed in a gamification approach, and also helps to identify some ways to improve it in order to increase the level of engagement in the social activities.

Due to its open design, the functionalities of SocialWire can be extended in multiple ways not addressed in this paper. As an example, we are currently working on a logging and tracking plug,in that keeps record of every action, event or activity done by a student. This is already possible for the site's administrators, but it was forbidden for normal users. In addition, although Elgg logs all the system activity in an internal database, these logs mix system data and user-generated data, so the data should be expurgated before being entirely useful.

The collected information can support two types of analysis:

- Elaborate reports for the instructors about the academic performance of their students and the development along the learning path. Maintaining a record of the interactions that took place among students is also interesting to identify easily their roles as leaders, followers, proactive or passive students, etc. The automatic construction of the ego-network of a student is possible with the plug-in.

- Elaborate reports with personalized recommendations to a student. Since the logged data includes semantic tagging (labels) and could be augmented to appeal to a suitable ontology, the plugin is the first step toward the automatic detection of knowledge gaps, weaknesses or skill lags. Once detected, specific recommendations could be made for each user according to their needs.

\section{REFERENCES}

[1] J. Rouet, and M. Puustinen, "Introduction to learning with ICT: New perspectives on help seeking and information searching", Computers \& Education, vol. 53, n. 4, pp. 1011-1013, 2009. http://dx.doi.org/10.1016/j.compedu.2009.07.001

[2] L. Rosen, Revired: Understanding the iGeneration and the way they learn. Palgrave McMillan, 2008.

[3] G. Small, and G. Vorgan, iBrain: Surviving the technological alteration of the modern mind. Harper Collins, 2008.

[4] J. Cross, Informal learning: Rediscovering the natural pathways that inspire innovation and performance. Pfeiffer, 2006.

[5] S. Bennet, K. Maton, and L. Kervin, "The digital natives debate: A critical review of the evidence", British Journal of Educational Technology, vol. 39, n. 5, pp. 775-786, 2008. http://dx.doi.org/10.1111/j.1467-8535.2007.00793.x

[6] K. Trinder, J. Guiller, A. Margaryan, A. Littlejohn, and D. Nicol, "Learning from digital natives: Bridging formal and informal learning”, Higher Education, vol. 1, pp. 1-57, 2008.

[7] J. Vassileva, "Towards social learning environments", IEEE Transactions on Learning Technology, vol. 1, n. 4, pp. 199-214, 2008. http://dx.doi.org/10.1109/TLT.2009.4
[8] J. Shell, The art of games design: A book of lenses. Morgan Kaufmann, 2008.

[9] S. Deterding, D. Dixon, R. Khaled, and L. Nacke, "From game design elements to gamefulness: Defining "gamification", International Academic MindTrek Conference: Envisioning Future Media Environments, New York, NY, 2011.

[10] J. Lee, and J. Hammer, "Gamification in education: What, how, why bother?", Academic Exchange Quarterly, vol. 15, n. 2, pp. 1$5,2011$.

[11] T. Connolly, E. Boule, E. MacArthur, T. Hainey, and J. Boyle, "A systematic literature review of empirical evidence on computer games and serious games", Computers \& Education, vol. 59, n. 2, pp. 661-686, 2012. http://dx.doi.org/10.1016/j.compedu.2012. 03.004

[12] L. Johnson, S. Adams, and M. Cummins, The NMC Horizon Report: 2012 Higher Education Edition. The New Media Consortium.

[13] L. Johnson, S. Adams, M. Cummins, V. Estrada, A. Freeman, and H. Ludgate, The NMC Horizon Report: 2013 Higher Education Edition. The New Media Consortium.

[14] L. Festinger, "A theory of social comparison processes", Human Relations, vol. 7, n. 2, pp. 117-140, 1954. http://dx.doi.org/10.1177/001872675400700202

[15] J. Hart, Social learning handbook. Center for Learning and Performance Technologies, 2011.

[16] J. Rodrigues, F. Sabino, and L. Zhou. "Enhancing e-learning experience with online social networks", IET Communications, vol.5, n.8, pp.1147-1154, 2011. http://dx.doi.org/10.1049/ietcom.2010.0409

[17] B. Thoms, "A dynamic social feedback system to support learning and social interaction in higher education", IEEE Transactions on Learning Technologies, vol. 4, n. 4, pp. 340-352, 2011. http://dx.doi.org/10.1109/TLT.2011.9

[18] http://www.elgg.org

[19] http://www.socialwire.es

[20] M. E. Sousa, J. C. López, M. Rodríguez, M. Fernández, and C. López, "Enabling social learning environments at the college level: A toolbox", IEEE Global Engineering Education Conference, Marrakesh, Morocco, 2012.

\section{AUTHORS}

M. E. Sousa-Vieira is with the Department of Telematics Engineering, University of Vigo, Spain (e-mail: estela@det.uvigo.es).

J. C. López-Ardao is with the Department of Telematics Engineering, University of Vigo, Spain (e-mail: jardao@ det.uvigo.es).

M. Fernández-Veiga is with the Department of Telematics Engineering, University of Vigo, Spain (email: mveiga@det.uvigo.es).

M. Rodríguez-Pérez is with the Department of Telematics Engineering, University of Vigo, Spain (email:miguel@det.uvigo.es).

C. López-García is with the Department of Telematics Engineering, University of Vigo, Spain (e-mail: candido@, det.uvigo.es).

Work supported by the European Regional Development Fund (ERDF) and the Galician Regional Government under agreement for funding the Atlantic Research Center for Information and Communication Technologies (AtlanTIC). This article is an extended and modified version of a paper presented at the EDUCON2015 conference held at Tallinn University of Technology, Tallinn, Estonia, 18-20 March 2015. Submitted 21 April 2015. Published as resubmitted by the authors 07 May 2015. 